\title{
The Food and Drug Administration
}

\author{
-A Protector of Public Health-
}

BY BRADSHAW MINTENER, LL.B.

$\mathrm{O}$ NE can hardly overestimate the importance of food, drugs, and cosmetics as a part of the human environment. Purity of these products is a health essential, yet any of the many thousands of products can deteriorate or be debased or contaminated in ways that will be injurious-even fatal - to the user. And, of course, any of them can be adulterated or mislabeled to serve the ends of deception and fraud.

Concern for health was largely responsible for the passage of the original Pure Food and Drugs Act of 1906. It had become known that poisonous preservatives and dyes were being used extensively in food products, that drug addiction was growing because of the unrestricted sale of remedies containing narcotics, and that a great many people were suffering tragic consequences because of their reliance on the claims being made in the labeling of widely advertised medicine. There is no doubt that the protection of health was and is the primary objective of our Federal food and drug laws, which will have their 50th anniversary in 1956.

The relation of drugs to health is direct and

Mr. Mintener, assistant secretary for Federal-State relations, Department of Health, Education, and Welfare, delivered the address on which this paper is based at the 73d annual convention of the Proprietary Association held in White Sulphur Springs, W. Va., May 24, 1955.

Vol. 70, No. 11, November 1955 obvious. The law requires them to be pure, fully potent, and labeled with adequate directions for safe and effective use. Food is required to be sound and wholesome, free of filth or harmful contaminants. Cosmetics, similarly, are required to be made from ingredients that are safe for use on the human body. Therapeutic devices must be labeled for their safe and effective use in treating diseases for which they are recommended. All these objectives are sought via the regulatory mechanism of prohibiting the shipment of misbranded or adulterated articles in interstate commerce.

In addition to the direct health importance of the foregoing requirements, the Federal Food, Drug, and Cosmetic Act imposes many requirements that have an indirect bearing on the health of the Nation. For example, it prohibits false and misleading claims on drugs which may lead the public to rely upon ineffective products rather than to seek competent medical care. Through food standards the law seeks to maintain the integrity of food so that consumers will get the nutritional values they have a right to expect. The enrichment of food under the law has made a decisive contribution to the elimination of deficiency diseases which once took thousands of lives every year.

Health violations-those which may be injurious to consumers-hold first place in the Food and I)rug Idministration's enforcement policy. Second are the sanitary violations, including those that may not be dangerous to 
health but offend common decency. Third are the economic violations-the marketing of products that cheat or swindle the consumer in some way, particularly products that camnot be detected by the reasonably alert purchaser.

While priority is given to those problems and cases involving health, there is an inevitable overlapping of these three fields of action. A sanitary violation may be a health violation. An economic violation, such as the substitution of an inferior or worthless ingredient in a food or drug, may also be a health violation. FDA inspectors are trained to work on all three. An inspector who is working on a suspected health violation will not overlook what he may find in the way of a filth violation or a serious economic violation. Sometimes the same product may violate in all three respects. For example, in the enforcement of the standards for cheese promulgated under section 401 of the act, the Food and Drug Administration is interested in this product from the following different standpoints :

-Health-whether the manufacturer has met the requirements for using pasteurized milk or storing the cheese a sufficient length of time to cause the death of any pathogenic organisms which may be present.

Sanitation-whether the cheese was made from clean milk or cream in a sanitary plant. This has its obvious relation to health.

Economic--whether the product has been made from the ingredients required to be used in that particular kind of cheese and contains the minimum fat content and not more than the maximum moisture content permitted by the standards. Such requirements can be tremendously important in preventing the debasement of food in order to gain an economic advantage.

In the past there have been various proposals to split up the work of the Food and Drug Administration among other Govermment units according to functions or to products. Actually the present arrangement is much more efficient because one inspector ordinarily handles all of these different kinds of work and is not concerned entirely with food, or with sanitation, or with economic frauds. He works on all of them, but of course health comes first. Ine to limitations of funds and staff, FI). now does very little by way of enforcing the law against economic violations, and it has had to reduce somewhat its work against sanitary violations. It is trying to maintain full protection against health violations, but even in this area there are some activities which should be strengthened.

\section{The Food Field}

What are some of the specific health activities carried on by the Food and Drug $\Lambda$ dministration in the food field? At the top of the list would be the efforts to prevent the use of poisonous or deleterious ingredients and contamination by dangerous micro-organisms. A few years ago the alertness of an FDA inspector prevented the shipment of a large lot of frozen peaches to which thiourea had been added to retard darkening. Thiourea is an acutely toxic chemical, capable of causing death.

On numerous occasions food and drug inspectors visiting food plants have spotted careless use of sodium fluoracetate (compound 1080). When used properly this compound is a very effective rodenticide, almost instantly fatal in extremely small amounts. Of course, it should be used only in locations where there cannot be any possibility of spillage on stored food products. Last fall thousands of pounds of frozen broccoli were voluntarily destroyed by packers after the inspectors found that several farmers had sprayed their fields with the wrong insecticide.

During a recent inspection of a plant making frozen chicken pies the FDA man found in the cold storage room a large number of pies that had soured due to accidental delay between making and freezing. None of the pies had been distributed, and the owner voluntarily destroyed the lot when he learned of their condition. Many people could have been made seriously ill if these pies had left the plant.

In the poultry and rabbit program the Food and I)rug Administration is concerned with keeping diseased poultry and rabbits out of food channels. Is a matter of fact, in all of the food programs, the agency is concerned with possible routes of contamination and hence possible vectors of infection as well as the adequacy of processing to prevent both the transmission of disease organisms and spoilage of the food which might cause illness. 
Somewhat closer to the interests of the proprietary drug industry is the program of checking on the enrichment of staple foods with vitamins and minerals to insure that these foods contain the full amount of these essential food elements. Also there is the dietary food program designed to insure adequate labeling of these foods to protect the health of diabetics, hypertensives, and others with special dietary requirements. Recent labeling regulations for low sodium foods and the vitamin testing activities carried on by the Division of Nutrition illustrate the health significance of the work done in this area.

The basic requirements of the Federal Food, Drug, and Cosmetic Act with respect to drugs may be summarized as safety, effectiveness, and correct labeling. Obviously, these are closely related to each other. Safety means safety for use according to the directions given on the label or recommended to the physician. Efficacy means effectiveness for the conditions for which the drug is offered or recommended. Obviously, a drug which lacks the potency declared on its label, or is otherwise ineffective, may be unsafe, particularly if used for serious illness.

One of our serious public health problems is reliance upon ineffective remedies and treatments promoted by quacks and charlatans, some of whom masquerade as scientific authorities. The Food and Drug Administration can deal with only one aspect of this broad problem by enforcing the law against interstate shipment of quack remedies and worthless devices.

\section{The Drug Field}

Some of the many programs in the drug field are concerned especially with the adequacy of controls over the compounding and labeling of drugs. The wrong ingredient or the wrong label can have disastrous consequences. So can the accidental contamination of drugs or the lack of sterility in products whose use requires them to be sterile. Sometimes in the interest of public health and safety it becomes necessary to clear the market of a drug that is dangerous because it is defective or misbranded. During the past fiscal year there were 32 such episodes. In all of these, fortumately, the records of the manufacturer were found adequate to trace all shipments, and it was not necessary to issue public warnings. In most instances the drug firms themselves were the first to notify the Food and Drug Administration when adverse reports were received regarding one of their products.

The law, of course, contains the multiple seizure provision in section $304($ a $)$ which enables the Government to remove from the market products which the courts have found to be adulterated or misbranded or, as the law says, "when the Secretary has probable cause to believe ... that the misbranded article is dangerous to health, or that the labeling of the misbranded article is fraudulent, or would be in a material respect misleading to the injury or damage of the purchaser or consumer." This section is obviously of great importance from a public health standpoint since it enables the Government to act effectively when the shipper of the goods is unwilling or unable to correct a violation.

Distribution of new drugs before their safety has been established pursuant to section 505 is an offense that is rarely encountered. When it is considered that the ten-thousandth new drug application became effective in June 1955, it is clear that the last 15 years have seen an outstanding advance not only in medical research but also in drug regulation for the protection of public health. It is particularly fortunate that many high-powered therapeutic agents discovered during this miracle drug era have been restricted to use under medical supervision. At the same time as experience is gained, it is found that some of these new drugs can be safely used by the layman. When that is the case the law requires that such drugs be labeled with adequate directions for such use. Recently, a definite procedure has been established for making this change in the status of a new drug. This regulation provides for public notice of such changes, allowing an opportunity for interested persons to state their views regarding the proposed change.

Among many other health responsibilities is the testing and certification of coal-tar colors to insure their harmlessness and suitability for use in food, drugs, and cosmetics. The testing and certification of insulin is vital to health because of the necessity for precise dosage in the use of this drug. 
Antibiotic drugs, which are administered to millions of persons for prevention or treatment of serious diseases, are likewise tested and certified by the Food and Drug Administration, thus guaranteeing to manufacturer, physician, and patient that they were safe and fully effective when they left the manufacturer's establishment.

There is the sampling and testing of such therapeutic devices as surgical sutures for required tensile strength and clinical thermometers for correct readings.

The cosmetic program is directed primarily toward protection of health. FD.I investigates particularly cosmetics which may be dangerous-those containing new ingredients, the safety of which may not be fully established, or those misbranded by seriously misleading claims.

Then there is the enforcement program against the illegal sale of prescription-legend drugs by pharmacists and others, especially such habit-forming and dangerous drugs as the baíbiturates and amphetamines.

Enforcement of the Caustic Poison Act is another of FDA's health responsibilities. The poison label and antidotes on certain household chemicals have helped greatly to reduce the toll of injuries and accidental deaths of children. I have been glad to learn of the interest the proprietary industry is taking in educating the public against carelessness in the use and storage of common household remedies. Many people seem to be oversold regarding the complete safety of some of these products, and they leave them where they can be readily sampled by young children.

\section{New Problems}

This discussion would not be complete without consideration of new health problems involving foods and drugs. Some of these are with us now. (Others loom on the horizon and must be anticipated by study on the part of both Govermment and industry.

Only a few weeks ago several thousand commercial packages of foods were exposed to an atomic explosion at the Nevada proving grounds. Similar tests on drugs have already been made and reported. The tests are made, of course, to learn what protection is provided by packaging and other factors against radioactive contamination. FDA already has considerable experience in this field and is conducting a series of training courses for State and local health workers to prepare them for their responsibilities in this area of civil defense.

An FIA Food Industry Advisory Committee, named by the National Research Council, is collaborating in studies of the vulnerability of food-processing plants to atomic, chemical, and bacterial warfare attack, and likewise of the decontamination measures needed in the erent of such attack.

But civil defense is not FI)A's only concern with regard to atomic energy. Radioactive drugs are becoming of increasing importance, and the radiation sterilization of foods is now the subject of intensive research by other Government and private organizations. FDA is not as active in this general area as it should be considering its health responsibilities. Similarly, such new developments as the increasing: employment of hormones and other potent drugs in livestock feeds, the increasing use of chemical additives in commercial food processing, and the proposed use of antibiotics as food preservatives demand that FDA's research facilities be expanded so that adequate attention will be given to the health side of these new developments.

We cannot consider the health responsibilities of the Food and Drug Administration without being impressed by the tremendous size of the job which this organization tries to accomplish. And when we consider the size of the organization-around 800 people working on enforcement operations, about 200 of them available for inspection work-we wonder how they do it. The fact is, of course, that they have been able to do only a partial job. For example, in 1954 they were able to inspect about 10 percent of the approximately 96,000 plants and warehouses which do a substantial interstate business in food, drugs, or cosmetics. At that rate each plant would be inspected about once in 10 years.

This obvious discrepancy between the size of the job and the facilities for the job led to the appointment of the ('itizens Advisory Committee on the Food and Irug Idministration. 
This committee of 14 distinguished, publicspirited citizens, financed by a special appropriation of Congress, has made a thorough investigation.

Based on its findings, the committee has recommended a substantial increase in the facilities and staff of the Food and Drug Administration to be accomplished in a period of 5 to 10 years.

The committee also recommended much greater emphasis on use of the techniques of trade and public education to accomplish the objectives of the law. For example, it recommended action to inform the public in specific terms against quackery, especially where real hazard to health is involved. To promote understanding of the prescription requirements of the law, the committee recommended that more effective means be found for educating physicians and pharmacists concerning these requirements and for developing mutual understanding between them and the public. Finally, it recommended increased representation of the Food and Drug Administration at meetings of State and local food and drug or health officials.

If these and other recommendations of the citizens committee can be carried out, I am sure there will be better understanding of the role of the Food and Drug Administration as a public health agency and better cooperation by all who are concerned about the effective enforcement of our pure food and drug laws.

\section{Poliomyelitis Vaccination Assistance Funds}

Funds have been allotted to each State under the $\$ 30$ million Poliomyelitis Vaccination $\mathrm{As}$ sistance Act signed by President Eisenhower August 12, 1955.

The law apportions the money in accordance with a formula which considers the number of unvaccinated children under age 20 and expectant mothers in each State, the relative per capita income of the State, and the per capita cost of vaccine. Of the $\$ 30$ million appropriated by Congress, $\$ 25$ million is available only for the purchase of vaccine, and $\$ 5$ million may be used for the costs of planning and conducting poliomyelitis immunization programs or for the purchase of vaccine. The funds are to be used by February 15, 1956.

While the vaccine may be administered by private physicians and by nonprofit organizations as well as by public agencies, the law provides that in vaccination programs conducted by public agencies no "means test" may be used to limit eligibility. Persons who are under 20 or are pregnant are eligible.

\begin{tabular}{|c|c|c|c|c|c|}
\hline $\begin{array}{c}\text { State } \\
\text { Alabama } \ldots\end{array}$ & $\begin{array}{l}\text { Allotment } \\
\$ 986,907\end{array}$ & $\begin{array}{c}\text { State } \\
\text { Massachusetts } \ldots \ldots\end{array}$ & $\begin{array}{l}\text { Allotment } \\
\quad \$ 686,853\end{array}$ & $\begin{array}{c}\text { State } \\
\text { South Dakota }\end{array}$ & $\begin{array}{l}\text { Allotment } \\
\quad \$ 156,769\end{array}$ \\
\hline Arizona $\ldots \ldots$ & 209,167 & Michigan ............ & $1,007,656$ & Tennessee $\ldots \ldots$ & 863,814 \\
\hline Arkansas & 646,637 & Minnesota $\ldots \ldots \ldots$ & 593,448 & Texas__. & $1,714,995$ \\
\hline California__._. & $1,597,864$ & Mississippi & & Utah $\ldots \ldots \ldots$ & 166,281 \\
\hline$\ldots \ldots \ldots$ & 240,586 & $i_{\ldots} \ldots \ldots \ldots$ & 48 & nont_........... & 718 \\
\hline icut ........ & 65 & $a_{\ldots} \ldots \ldots \ldots$ & 11 & $\ldots \ldots$ & 384 \\
\hline re $\ldots \ldots \ldots \ldots$ & 42,118 & $a_{-\ldots \ldots} \ldots \ldots$ & 62 & ngton ........... & 315 \\
\hline of Columbia... & 100,608 & $a_{\ldots} \ldots \ldots \ldots$ & 41 & Virginia $\ldots \ldots \ldots$ & 270 \\
\hline Florida $\ldots \ldots$ & 677,027 & ampshire...... & 295 & ssin . . . . . . . & 539 \\
\hline$\ldots$ & 992,329 & New Jersey _ . . . . . . . & 86 & ing ............ & 069 \\
\hline Ida & 138,225 & New Mexico .......... & 754 & 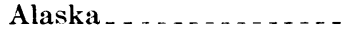 & 240 \\
\hline Illinois _. . & $1,133,062$ & New York ............ & 1,72 & ii ..... & 100,359 \\
\hline 1... & 640,435 & North Carolina........ & 1,25 & o Rico $\ldots \ldots . . .$. & $1,169,790$ \\
\hline$\ldots \ldots \ldots$ & 490,12 & North Dakota......... & 18 & Islands.......... & 941 \\
\hline$\ldots \ldots$ & 361 , & $\mathrm{Oh}$ & $1,167,504$ & 1 Zone $\ldots . . . . . . . . .$. & 15,702 \\
\hline Ken & 8 & $\mathrm{ma} \ldots \ldots \ldots$ & 49 & $\ldots$ & 751 \\
\hline na $\ldots \ldots \ldots$ & & $\ldots \ldots$ & 842 & American Samoa $\ldots . . .$. & 12,758 \\
\hline$\ldots \ldots \ldots$ & & $\ldots$ & 1,5 & & \\
\hline Maryland ............ & 385,123 & $a_{\ldots} \ldots$ & 701,198 & & \\
\hline
\end{tabular}

